\title{
MUJERES PROTAGONISTAS: PROTESTA EN EL PAÍS Y PANDEMIA EN LA CASA
}

Sandra Palestro Contreras 


\section{SANDRA PALESTRO CONTRERAS}

Feminista, socióloga, integrante de la Coordinación Nacional de la Red Chilena contra la Violencia hacia las Mujeres. 


\section{MUJERES PROTAGONISTAS: PROTESTA EN EL PAÍS Y PANDEMIA EN LA CASA}

Formalmente, Chile cambió de escenario en un corto lapso, y de una crisis social que llevaba más de cuatro meses de explosión masiva y se tomaba las calles de las principales ciudades del país pasó a una crisis sanitaria que confinó a la población en las casas por tiempo indefinido.

La revuelta popular, iniciada en octubre de 2019, estaba expresando la rabia acumulada por la desigualdad que produce y reproduce este sistema de dominación patriarcal capitalista, extremado en su versión neoliberal. Todas las instituciones estaban deslegitimadas, sumidas en la corrupción y el repudio de la ciudadanía.

Aunque los movimientos sociales ya venían denunciando con masivas movilizaciones los abusos, las injusticias, el racismo, la misoginia, incluso la burla de las élites política y económica, estas se sorprendieron del estallido social ${ }^{1}$. Sus análisis no lo habían consignado.

Millones de personas se tomaron las calles de todo el país, "Chile despertó" fue la consigna. Sin embargo, Chile no había estado dormido, estallidos parciales y sectoriales se venían produciendo desde hace muchos años, con magros resultados: algunos protocolos, otras tantas leyes, políticas públicas, mesas de trabajo, muchas promesas a futuro, pero el sistema patriarcal capitalista seguía (sigue) igual. Los problemas estructurales no han sido tocados, la explotación de la fuerza de trabajo, la depredación de la naturaleza, la violencia contra las mujeres, la represión y la fuerza para la resolución de conflictos sociales, nada de eso ha quedado siquiera como tema pendiente, son asuntos zanjados cuando baja la presión social.

1. Solo si nos remontamos a los últimos quince años: en 2006 el "pingüinazo" de los estudiantes secundarios; en 2011 los movimientos sociales liderados por el movimiento estudiantil universitario; el movimiento ecologista contra la represa Hidroaysén; la comunidad gay y vastos sectores sociales movilizados por el asesinato de Daniel Zamudio. Desde 2012 en adelante, las protestas regionales de Magallanes, Aysén y Arica, y las comunales de Calama, Petorca, Pelequén, Quintero-Puchuncaví, Freirina, Chiloé y Constitución, entre otras. En 2016 hubo manifestaciones contra las Administradoras de Fondos de Pensiones (AFP). En 2018 y 2019, las feministas protagonizaron la movilización. Y en todo este periodo, la inclaudicable lucha del pueblo mapuche por sus reivindicaciones históricas, que les ha significado vivir en zonas militarizadas y soportar allanamientos y hostigamiento permanente, la que continúa sin solución. 
Muchas protestas habían congregado a mujeres y hombres que paralizaron ciudades, incluso regiones enteras. Sin embargo, eran invisibles las personas, sus difíciles condiciones de vida, su abandono aun cuando comparten territorio con prósperas empresas y cuantiosos recursos naturales estratégicos. De ellas, los medios de comunicación tradicionales solo dejaban relatos de condena e imágenes de "alteración del orden público". Exaltaban las bondades de la manifestación pacífica, colorida y alegre, mejor aun si era familiar, mejor aun si era en días domingo. Era la forma de presión admitida, la que obtenía permiso firmado por las autoridades. Aunque así fueran y al final se produjeran enfrentamientos solo de unos pocos "encapuchados" con carabineros, esta era la noticia y el colofón de la protesta multitudinaria, nunca quedaba claro el porqué se protestaba. Al día siguiente volvía la normalidad a las ciudades hasta otra manifestación pacífica de millones de personas en las calles que las élites no veían ni escuchaban.

El potencial transformador o al menos remecedor de la crisis social que estalló en octubre, que alertó a la élite dominante y al país entero fue, por una parte, la persistente conjunción de masividad, desobediencia y destructividad de todo lo que pudiera llamarse "orden", "progreso", "desarrollo" y sus íconos materiales (bancos, financieras, centros comerciales, supermercados, etc.), que trastocó el funcionamiento inercial de la producción y el consumo. Era una multitud en las calles del país deseando cambiarlo todo. Se estaba atacando el corazón de este sistema que significa la explotación de las mayorías, la deshumanización de la vida, la depredación de la naturaleza y la destrucción del planeta. Y, con ello, a la institucionalidad política que lo ha permitido y reproducido.

Por otra parte, la paulatina articulación de diversos sectores organizados de la población y su extensión en los distintos territorios del país a través de asambleas deliberativas y manifestaciones solidarias de todo tipo ponía en jaque los sacrosantos principios neoliberales del individualismo, el exitismo, la competencia, y unía a las personas en reflexión colectiva, participación y solidaridad. Así también, era una articulación que experimentaba incipientes formas de conducción colectiva desde una base social heterogénea.

El gobierno, sin empatía ni capacidad de diálogo, respondía con represión y medidas de control de la población. Las fuerzas de orden y seguridad fueron reforzadas por militares a raíz de la declaración de Estado de Excepción Constitucional de Emergencia en varias regiones y toque de queda en algunas ciudades del país. En tanto, el presidente se dirigía a la ciudadanía para dar a conocer su nueva agenda social, señalando: "Hemos escuchado fuerte y clara la voz de la gente expresando pacíficamente sus problemas, sus dolores, sus sueños y sus esperanzas de una vida mejor". Por su parte, los medios de comunicación indicaban: "El presidente Sebastián Piñera presentó una contundente agenda social 
que establece beneficios urgentes para los sectores vulnerables, la clase media, los adultos mayores y los más postergados". Con pequeños paliativos económicos y este lenguaje, el gobierno pretendía apagar el estallido social. Cuando se quedó prácticamente sin apoyo y sus esfuerzos por volver a la "normalidad" eran en vano, desde la misma deslegitimada institucionalidad parlamentaria intentaron desplazar el conflicto hacia la formulación de una nueva Constitución Política.

El 3 de marzo, el Covid-19 llegó a Chile. El presidente presentó el Plan de Acción del Gobierno para prevenir el contagio de la población, que incluía adquisición de nuevo equipamiento, refuerzo de la red de salud, controles migratorios y el despliegue de un operativo de detección y tratamiento. Ese mismo día se conocía el primer contagiado de Coronavirus en el país.

Las y los protagonistas de la protesta habían vivido una implacable represión, cientos de jóvenes sufrieron daños irreparables en sus ojos, 31 personas murieron, miles fueron encarceladas, muchas sufrieron torturas y abusos sexuales mientras los contenidos de la revuelta popular tendían a desvanecerse tras la agobiante violación de los derechos humanos.

El estallido social tuvo el protagonismo de las mujeres como una de sus principales características. El feminismo venía en alza sostenida, tanto en conciencia, decisión y fuerza como en la masividad de las manifestaciones públicas, entre ellas, la marcha Ni una Menos (2016), que expresaba rabia y dolor por los femicidios; la toma de universidades y liceos (2018), que se inició contra el acoso sexual en esos planteles y culminó contra el sexismo en la educación y el patriarcado; el masivo 8 de marzo (2019) que unió las diversas luchas de las mujeres; y los 25 de noviembre de cada año, contra la violencia hacia las mujeres en todos los ámbitos. El 8 de marzo, que marcaba el año de protestas durante la dictadura cívicomilitar y esta vez, en 2020, iniciaba una segunda etapa del estallido social, congregó a más de dos millones de mujeres en las calles de todo Chile y fue la manifestación más multitudinaria que se conoce.

La crisis sanitaria por Covid-19 permitió al gobierno tomar el control de la población. Llamó a confinarse en las casas y decretó cuarentenas parciales, otro intento para mantener la normalidad y no afectar la economía. Una vez más convocó a los militares y el 18 de marzo declaraba Estado de Excepción Constitucional de Catástrofe; cuatro días después se imponía el toque de queda en todo el país. Este Estado de Excepción permite, entre otras cosas: dar mayor seguridad a los hospitales y todos los sitios de atención de salud; proteger la cadena logística y traslado de insumos médicos; facilitar el cuidado y traslado de pacientes y personal médico y la evacuación de personas; resguardar el cumplimiento de las cuarentenas y medidas de aislamiento social; garantizar la cadena de producción y distribución para asegurar el normal abastecimiento de la población, y proteger y resguardar las fronteras. Además, establecía que los jefes 
de la Defensa Nacional asumirían el mando de las Fuerzas de Orden y Seguridad Pública en las zonas respectivas para velar por el orden público y reparar o precaver el daño o peligro para la seguridad nacionat.

Es decir, el gobierno enfrentaba la crisis sanitaria declarando la guerra no al virus sino a la población. Sin duda, en su imaginario estaba el estallido social y había encontrado la oportunidad para imponer la obediencia. Más tarde, el presidente se tomaría una fotografía en la Plaza de la Dignidad, ícono de la revuelta popular, para refrendar su "triunfo".

En su relato no cabían mensajes llamando a la población a la unidad y la colaboración, a la solidaridad y los cuidados mutuos, a mostrar un liderazgo transparente y cercano. La conducción política del gobierno siguió la misma línea represiva de siempre, aunque fuera una situación excepcional: con la lógica de dominación masculina que se manifiesta en un lenguaje guerrero de batallas y héroes y en la exaltación de las Fuerzas Armadas y de Orden; con políticas estandarizadas con el rasero de quienes detentan el poder político y económico, asegurados en presente y futuro, en tanto las mayorías viven en hacinamiento, cesantía, falta de alimentos, agua y salud; competitiva y soberbia, que se vanagloria de récords exitosos en la región latinoamericana y no escatima en la comparación con países del norte: "La respuesta de Chile frente a esta epidemia debe ser eficaz y permitirnos estar entre los países que lograron sortear con éxito esta tremenda amenaza a la salud...", dijo el presidente Piñera. Por las medidas adoptadas, "hemos recibido felicitaciones hasta el cansancio", decía el ministro de Salud, Jaime Mañalich, mientras la vocera de gobierno, Karla Rubilar, comparaba las cifras de Chile con las de Alemania sin ningún pudor. Tantos éxitos en el plano sanitario contra un virus que afecta a todas $\mathrm{y}$ todos por igual no consideraban sus efectos diferenciados por la desigualdad económica y social ${ }^{3}$. Principalmente, en sectores empobrecidos, en zonas rurales, indígenas, inmigrantes, entre personas con capacidades diferentes y jefas de hogar.

La manipulación del lenguaje es total: todo lo que el gobierno hace y no hace es "histórico"; el presidente, para quien ya no había más improperios, empezó a ser

2. El subrayado es de la autora del texto.

3. Ministerio de Desarrollo Social y Familia. Informe de Desarrollo Social 2019. La pobreza multidimensional en el país en 2017 era de 20,7 por ciento. Su desglose: urbano: 18,3 por ciento, rural: 37,4 por ciento; indígena: 30,2 por ciento, no indígena: 19,7 por ciento; chileno: 20,5 por ciento, no nacido en Chile: 24,6 por ciento; personas sin discapacidad: 19,9 por ciento, personas con discapacidad: 24,8 por ciento. Respecto de los hogares monoparentales, la pobreza multidimensional entre hombres y mujeres jefes de hogar es bastante similar. En la pobreza y la pobreza extrema por ingresos se observa una diferencia en desmedro de las mujeres. Pobreza hombres: 6,4 por ciento, pobreza mujeres: 9,2 por ciento; pobreza extrema hombres: 1,8 por ciento, pobreza extrema mujeres: 2,7 por ciento. 
nombrado por sus ministros como "su Excelencia el Presidente de la República"; los empresarios comenzaron a nombrar a los trabajadores como "nuestros colaboradores"; en el momento crítico de la cuantía de contagios hablaron de un "quiebre" en la toma de test y sus resultados, nunca de la escasez de reactivos. Ya desde mucho antes, el pueblo se había convertido en "la gente", los sectores pobres o, mejor dicho, empobrecidos, pasaron a llamarse "vulnerables"; los despedidos de sus trabajos ahora son "desvinculados"; los derechos pasaron a ser "beneficios", etc., etc. "... Por eso, cuando hablamos de la manipulación de las palabras nos referimos a la cirugía más o menos hábil a que con frecuencia se somete a las palabras desvirtuando su sentido auténtico y poniéndolas al servicio de intereses concretos"4. Cuando reparamos en esto, la salud mental se resiente, nos invade la indignación y la desconfianza.

Las comunicaciones son controladas por el gobierno y poderosos grupos económicos, por tanto, muestran lo que es conveniente a sus intereses. Entregan información manipulada en el lenguaje y sesgada o directamente falsa sobre la real situación del país. En este contexto de desconfianza y temor por el contagio y la muerte, las empresas siguen contaminando el aire, saqueando el agua de territorios agrícolas, depredando el mar y los ríos, la tierra y las montañas. Es lo que Naomi Klein llama "la doctrina del shock", que es la estrategia política de utilizar las crisis a gran escala para impulsar políticas que sistemáticamente profundizan la desigualdad y enriquecen a las élites, instaurando lo que ha denominado "capitalismo del desastre" 5 . En momentos de crisis, señala Klein, "la gente tiende a centrarse en las emergencias diarias de sobrevivir a esa crisis, sea cual sea, y tiende a confiar demasiado en los que están en el poder".

Así, mientras el gobierno y las élites utilizan política y económicamente la emergencia sanitaria copando la información y las comunicaciones, la gran ausente en sus relatos ha sido la solidaridad que despliega el pueblo en los distintos territorios del país y que ha hecho posible que la catástrofe no sea total.

Los movimientos sociales, las organizaciones de larga data, aquellas creadas durante el estallido y las que se han re/creado en esta crisis sanitaria, siguen en actividad y no solo denuncian por medios alternativos la realidad que provocó la revuelta social y que se muestra descarnadamente en la pandemia, sino que también se han puesto en marcha para paliar los efectos sociales de la crisis sanitaria y el confinamiento: la cesantía, el hambre, la violencia contra las mujeres, entre otras.

4. Seco, Manuel (de la Real Academia Española). La manipulación de las palabras. Boletín del Instituto de Estudios Giennenses No180. 2002. pp. 7-18.

5. Entrevista a Naomi Klein. "El desastre perfecto: Naomi Klein y el coronavirus como doctrina del shock”. Lavaca, 23 de marzo, 2020. 
En esta perspectiva, las organizaciones feministas desarrollan acciones urgentes contra la violencia, puesto que, como ha sucedido en muchos países, esta ha recrudecido al concentrarse en el espacio doméstico todas las dinámicas de la vida. Así, la crisis ha mostrado los diferenciados efectos del confinamiento para las mujeres y las niñas en general, y las particularidades que conlleva en la diversidad de mujeres de acuerdo a la clase, la etnia, la nacionalidad, entre otros factores.

Las consultas telefónicas de mujeres por violencia crecieron en un 70 por ciento cuando empezó a regir la cuarentena. "El registro muestra que entre el 20 y el 22 de marzo hubo 532 llamadas, mientras que entre el 27 y el 29 de marzo - la cuarentena comenzó el día 26- la cifra subió a 907"'. Sin embargo, han disminuido las denuncias en un 18,6 por ciento, lo cual resulta obvio debido a las restricciones que implican la cuarentena y el toque de queda, y a la insuficiencia de las medidas adoptadas por el gobierno para la protección de las mujeres. Hombres han cometido 17 femicidios $^{7}$ y los femicidios frustrados aumentaron en un 250 por ciento solo en marzo, en comparación a marzo de 2019. Según la Fiscalía Nacional, "se explica porque existe una mayor comprensión del fenómeno del femicidio... lo que ha permitido una mejor calificación de hechos que antes eran calificados como lesiones graves", lo cual es un logro, aunque también podríamos hipotetizar que la coexistencia de más personas en el mismo espacio, casa o vecindario ha permitido proteger a las mujeres en momentos críticos.

Agresiones físicas y femicidios son las manifestaciones de violencia que dan a conocer los medios de comunicación junto a las medidas que adopta el cuestionado Ministerio de la Mujer y la Equidad de Género, lo cual ha vuelto a situar la violencia hacia las mujeres en las relaciones de pareja, en el ámbito privado/doméstico, amenazando una vez más con su despolitización como problema estructural que se produce y reproduce en todos los ámbitos y que afecta, de una manera u otra, a todas.

En el ámbito económico, las mujeres son invisibles. Se han puesto todas las alertas en que muchas empresas han quebrado y otras han restringido al máximo su funcionamiento, lo que aumenta la cesantía y acarrearía peligro para la manutención de las familias. El Estado responde con urgente apoyo a las empresas para mantener en marcha la economía, pero en la vida cotidiana, las mujeres siguieron ocupándose de las variadas labores que demanda el trabajo doméstico, con hijos e hijas en casa y personas adultas mayores y/o enfermas a su cuidado.

6. Cuevas, Carolina, Ministra (s) de la Mujer y la Equidad de Género. Entrevista en canal TV 24Hrs.cl. 3 de abril, 2020.

7. Red Chilena contra la Violencia hacia las Mujeres. Registro de femicidios en www. nomasviolenciacontramujeres.cl 
Según datos de un estudio de la Fundación Sol ${ }^{8}$, un 96,6 por ciento de las personas declaradas "inactivas por quehaceres del hogar" son mujeres. Si esta categoría fuera medida como personas ocupadas, la tasa femenina en el empleo subiría de cerca de un 50 por ciento a un 68,8 por ciento. El concepto de "inactividad" invisibiliza el trabajo que realizan las mujeres fuera del mercado laboral.

Incluso quedan fuera de este ámbito los trabajos remunerados precarios, informales, que realizan la mayoría de mujeres de hogares empobrecidos y monoparentales. Son ellas las que se exponen cada día en las calles con ventas de cualquier producto que les reportan apenas el sustento diario para su grupo familiar. Tampoco son consideradas las mujeres que realizan trabajos remunerados inestables, domésticos o de temporada, a honorarios o por tiempo acotado, y que en esta crisis se han quedado sin ingresos. Agrava la situación el drama humanitario que se ha producido en las últimas semanas con cientos de familias de distintos países latinoamericanos que tenían estas condiciones laborales y que hoy esperan fuera de los consulados, en las calles, apoyo para regresar a su país.

En el ámbito laboral, no parece importar el teletrabajo que ahora desempeñan las mujeres, que además de ser ilimitado — como denuncian muchas-, les ha significado concentrar en el mismo espacio una carga más a las habituales. Cuando dicen que este "llegó para quedarse", no es difícil suponer lo que implicará para las mujeres si los hombres no asumen a la vez su corresponsabilidad frente al trabajo doméstico y de cuidados.

$\mathrm{Ni}$ el trabajo doméstico de reproducción y cuidados ni el comunitario, que realizan mujeres, mayoritariamente, cuentan para la producción y la economía del país, aunque estas se basen precisamente en ellos, y como se ha demostrado en crisis sociales, ambientales, sanitarias y económicas, han sido fundamentales para que la sociedad pueda satisfacer sus necesidades más apremiantes y se preserve la vida.

Son mujeres, principalmente, quienes han respondido con prontitud para sustentar las necesidades básicas en esta crisis. Han sostenido la solidaridad y la organización para hacer frente al hambre, los cuidados de salud y la cesantía, compartiendo los escasos recursos de los que disponen o que provienen de otras solidaridades. Ollas comunes, compras comunitarias, trueques, elaboración de comidas o implementos sanitarios para la venta son algunas entre las múltiples iniciativas desarrolladas.

8. Barriga, Francisca (co-autora). "No es amor, es trabajo no pagado. Un análisis del trabajo de las mujeres en el Chile actual”. Fundación Sol, 2020. Entrevista en Mujeres en Sintonía, programa radial de la Red Chilena contra la Violencia hacia las Mujeres. www.nomasviolenciacontramujeres. $\mathrm{cl} /$ mujeres-en-sintonia-3 
Se han formado redes feministas para la orientación en situaciones de violencia, la contención psicológica, el apoyo jurídico, la provisión de alimentos. Se han realizado cientos de seminarios, talleres, conversatorios para la discusión política, la autoformación y la reflexión sobre nuevas perspectivas de vida.

Estas acciones de feministas en la emergencia sanitaria son parte de sus luchas permanentes por erradicar la violencia hacia las mujeres, por el cuidado de las semillas, la tierra, la naturaleza; la defensa del agua y los territorios, de los derechos humanos. No pretenden subsidiar las obligaciones del Estado, sino que son distintas formas de resistencia de las mujeres frente a un sistema inhumano las que en tiempos de crisis se hacen más visibles.

Son los pequeños gestos de rebeldía cotidiana de las mujeres los que van cambiando la vida, decía Julieta Kirkwood, o "la invencible revolución permanente de las mujeres" a que se refiere Angélica Illanes", que encarna una modalidad de hacer política o su revolución emancipatoria no solo desde los aparatos culturales y políticos, sino también desde las relaciones familiares y personales. Ciertamente, ni los gestos de rebeldía ni la revolución emancipatoria de las mujeres son consignados en la historia androcéntrica oficial, porque supuestamente no somos capaces de producir ideas ni transformaciones profundas que pudieran llamarse históricas. Sin embargo, uno a uno y multiplicados por miles, estos gestos contienen propuestas para una nueva sociedad, para una economía sustentable, para el bienestar de toda la población. Son experiencias productivas que se desarrollan fuera de los mercados, solidarias, colaborativas, sin relaciones de poder opresivas. Es la politicidad de las mujeres que pone la vida en el centro de la acción colectiva.

Más conscientes de los efectos perversos de la desigualdad en situaciones de catástrofe, hagamos imposible la vuelta a la "normalidad" tal como la conocíamos. Tenemos que repensar el trabajo, la economía, la política, las relaciones humanas a la luz de las prácticas cotidianas que hemos desplegado las mujeres a lo largo de la historia. No queremos ser parte de este sistema patriarcal, capitalista, colonialista, racista, que ha precarizado la vida y destruido el planeta.

9. Illanes, María Angélica. Nuestra historia violeta. Feminismo social y vidas de mujeres en el siglo XX: una revolución permanente. Santiago, LOM, 2012. 